\title{
The 22q11 microdeletion syndrome in children
}

\author{
ALEKSANDRA LEWANDOWICZ-USZYNSSKA ${ }^{1,2}$, KATARZYNA ZWONARZ $Z^{3}$, JOANNA CHMIELARSKA ${ }^{2}$ \\ ${ }^{1} 3^{\text {rd }}$ Department and Clinic of Pediatrics, Immunology and Rheumatology of Developmental Age, Wrocław Medical University \\ ${ }^{2}$ Department of Immunology and Pediatrics, J. Gromkowski Provincial Hospital \\ 32Department of Clinical Immunology and Transplantology, Children's University Hospital, Jagiellonian University Medical College, Cracow
}

\begin{abstract}
DiGeorge syndrome is a primary immunodeficiency with microdeletion 22q11. Prenatal diagnosis is possible. Typical disorders are heart defects of heart and large vessels, hypoplasia of the parathyroid glands, dysmorphia, no thymus and immune deficiency.

The primary problem is the heart defect requiring cardiac surgical intervention. Due to the severity of the operation, immunodeficiency often goes into the background. Infections are associated with cardiovascular abnormalities. The immune deficit is omitted without proper treatment including isolation of the patient, substitution of i.v. immunoglobulin, chemo-prophylaxis. Blood products must be irradiated. What should be applied is oncology alertness and limitation of X-ray should also be noted. A comprehensive care reduces infections and improves the quality of life.
\end{abstract}

Key words: DiGeorge syndrome, diagnosis, standard procedure.

(Centr Eur J Immunol 2013; 38 (2): 271-275)

\section{aIntroduction}

DiGeorge syndrome (often referred to as the $22 \mathrm{q} 11.2$ deletion syndrome) is one of well-defined primary immunodeficiency disorders associated with large defects [1]. The syndrome was described for the first time in 1968 by Angelo DiGeorge [2]. The literature still describes a similar coexistence of deficiencies, operating under the names:

- thymic hypoplasia with concomitant hypocalcemia,

- Takao syndrome (conotruncal anomaly face syndrome),

- velo-cardio-facial syndrome (VCFS, Shprintzen syndrome),

- Cayler cardiofacial syndrome,

- Opitz syndrome: genitourinary system irregularities in addition to cleft palate, heart defects and mental retardation,

- CATCH-22 syndrome (an acronym formed from the first letters of observed disorders: C - cardiac defects, A abnormal faces, $\mathrm{T}$ - thymic hypoplasia, $\mathrm{H}$ - hypocalcemia from parathyroid aplasia, 22 - chromosome 22 microdeletions).

The syndrome affects 1 in 3000-5000 live births. 90\% of cases are 22q11.pter chromosome deletions (mostly microdeletions) or 10p13 deletions (much less often) [3]. It is assumed that $72-90 \%$ of cases are a de novo genetic defect. The remaining patients have an autosomal dominant mutation inherited from the father or mother (three times more), and therefore discrete features of dysmorphia are observed in parents (they are asymptomatic carriers of the 22q11.2 microdeletion) $[4,5]$. The risk of the syndrome in any subsequent child is $1: 2(50 \%)$.

The defect can be detected by fluorescence in situ hybridization (FISH) that uses probes targeted only to a critical region [3, 6-8]. MLPA. Due to the high variability of symptoms with the same kind of a genetic defect (loss of genes in the 22q11.2 region), the medical image probably also depends on a group of other genes, and therefore it cannot be prenatally determined based on diagnosed microdeletions whose symptoms will occur. Therefore, due to a large variability of the clinical picture, it is currently recommended to use the term "22q11.2 microdeletion syndrome". The presence of characteristic mutations detected using the FISH technique is not confirmed in approximately $10 \%$ of patients diagnosed with the symptoms of the $22 \mathrm{q} 11.2$ microdeletion syndrome, because 10p13, 17p13 and $18 \mathrm{q} 21.30$ deletions or defects within individual genes are also possible.

The symptoms of the syndrome relate to different systems and organs in the form of disorders (they can occur in a variety of interrelations):

Correspondence: $\mathrm{dr}$ n. med. Aleksandra Lewandowicz-Uszyńska, $3^{\text {rd }}$ Department of Paediatrics, Clinic of Immunology and Rheumatology of Developmental Age, Wroclaw Medical University, ul. Koszarowa 5, 51-149 Wrocław, Poland, tel. +48 713925397 , fax +48 713925 396, e-mail: alusz1 @ poczta.onet.pl 
Table 1. ESID criteria for diagnosing the microdeletion syndrome in the 22q11.2 chromosomal region [8, 9]

\begin{tabular}{|c|c|c|}
\hline Definitive diagnosis & Probable diagnosis & Possible diagnosis \\
\hline $\begin{array}{l}\text { Heart or great vessels defect: } \\
\text { - patent ductus arteriosus } \\
\text { - tetralogy of Fallot } \\
\text { - interrupted aortic arch } \\
\text { - aberrant right subclavian artery }\end{array}$ & Male or female child & Male or female child \\
\hline $\begin{array}{l}\text { - Hypocalcaemia lasting } \\
\text { more than } 3 \text { weeks, } \\
\text { requiring treatment } \\
\text { - Reduced number of } \mathrm{CD} 3+ \\
\text { T lymphocytes (less than } \\
500 / \mathrm{mm} \text { ) }\end{array}$ & $\begin{array}{l}\text { Reduced number of CD3+ } \\
\text { T lymphocytes (less than } \\
1500 / \mathrm{mm}^{3} \text { ) }\end{array}$ & $\begin{array}{l}\text { Reduced number of } \mathrm{CD} 3+\mathrm{T} \text { lymphocytes } \\
\text { (less than } 1500 \text { per } \mathrm{mm}^{3} \text { ) }\end{array}$ \\
\hline Deletion of chromosome 22q11.2 & Deletion of chromosome 22q11.2 & $\begin{array}{l}\text { One of the following disorders: } \\
\text { - heart defect } \\
\text { - hypocalcaemia lasting more than } 3 \text { weeks, } \\
\text { requiring treatment } \\
\text { - dysmorphic facial features or palatal anomalies }\end{array}$ \\
\hline $\begin{array}{l}\text { Definitive diagnosis of the } \\
\text { complete DiGeorge syndrome }\end{array}$ & \multicolumn{2}{|c|}{$\begin{array}{l}\text { Reduced number of CD3+ T lymphocytes (less than } 50 \text { per }^{3} \mathrm{~mm}^{3} \text { ) and all of the following: } \\
\text { - documented lack of thymus as less than } 50 \text { fresh thymic cells }(\mathrm{CD} 3+\mathrm{CD} 45 \mathrm{RA}+\mathrm{CD} 62 \mathrm{~L}+ \\
\text { cells/per } \mathrm{mm}^{3} \text { ) and/or TRECs }<100 / 100000 \mathrm{~T} \text { cells } \\
\text { - hypoparathyreosis } \\
\text { - heart defect }\end{array}$} \\
\hline
\end{tabular}

- absence or dysfunction of the thymus and the associated immune disorders,

- facial defects and abnormalities,

- cardiovascular abnormalities,

- metabolic and endocrine disorders,

- urological and nephrological abnormalities,

- neurological disorders.

In view of the wide variety of clinical pictures, criteria of definitive, probable and possible diagnosis have been developed to facilitate the diagnosis (Table 1) [8, 9].

\section{Immune disorders}

T lymphocytes are divided into subpopulations having different functions and characterized by a specific pattern of surface antigens. Differentiation of T cells occurs in the thymus. Precursors of T lymphocytes from bone marrow penetrate the cortical part of the thymus through the circulatory path and differentiate into thymocytes (CD4+, CD8). There is a positive selection of T cells in the cortex, but this refers only to cells that recognize MHC antigens through their TCR receptors. The others undergo apoptosis. Subsequently, the cells migrate into the cortical part of the thymus where in the course of further maturation, with the use of chemokines, the expression of surface antigens and antigen receptors specific to T cells occurs. A negative selection in turn takes place in the cortical part whereby cells highly reactive to self-antigens are eliminated. The process of the negative selection results in a loss of approximately $90 \%$ of the thymocyte population. At this stage, thymocytes eventual- ly differentiate into cells that have only one of the antigens, CD4 or CD8, and are exported to the periphery [10].

Very frequently no thymus shadow on chest X-ray films is found in patients with the 22q11.2 microdeletion syndrome, which is of diagnostic importance and involves the presence of abnormalities in cellular and/or humoral immunity (deficit of T cells, especially CD4+, deficiency of major classes of immunoglobulins, IgG subclasses and specific antibodies) (Table 2). There are two forms of this syndrome: complete with severe impairments of cellular response and impaired humoral response, and partial in which the immune response is slightly impaired, and spontaneous remission of these irregularities is possible. A PHA-stimulated lymphocyte proliferation assay is useful in determining the form of the syndrome [11]. The response to vaccination is most often correct in the majority of patients diagnosed with impaired synthesis of specific antibodies (in patients with incomplete 22q11.2 microdeletion syndrome) [12]. An increased incidence of adverse vaccine reactions is not observed in this group [13]. Immunization with live vaccines is contraindicated in the case of low T-cell values or it should be postponed until the anomalies are resolved.

Data available in the literature show that $80 \%$ of immune abnormalities observed in the neonatal period may subside spontaneously in the first years of life [14]. It is now believed that in children with congenital absence of thymus or thymus removed during a cardiac surgery, the maturation and differentiation of T lymphocytes still occur outside the thymus, presumably from $\mathrm{T}$ lymphocytes present in the gastrointestinal tract [15]. The immune system disorders 
Table 2. Most common immunological abnormalities observed in 22q11.2 microdeletion syndrome patients [3, 11]

\begin{tabular}{lll}
\hline & \multicolumn{2}{c}{ Microdeletion syndrome } \\
\cline { 2 - 3 } & $\begin{array}{l}\text { complete } \\
\text { with severe immune disorders }\end{array}$ & $\begin{array}{l}\text { partial } \\
\text { immune response is slightly impaired }\end{array}$ \\
\hline Absolute number of CD3+ T cells & $\begin{array}{l}\text { significantly reduced in the group of the } \\
\text { youngest patients }\end{array}$ & transient slight decrease \\
\hline Quantitative abnormalities of CD4+ T cells & high & small \\
\hline PHA blast transformation test & impaired & correct \\
\hline Concentrations of IgG, IgA, IgM & reduced (rarely) & correct \\
\hline Specific antibodies & impaired synthesis & impaired synthesis \\
\hline
\end{tabular}

result in recurrent infections of the respiratory and gastrointestinal tracts, most often of viral, fungal and protozoan aetiology and less often of bacterial etiology.

The occurrence of immunodeficiency in the 22q11.2 microdeletion syndrome is also related to an increased risk of autoimmune disease, as in other types of PID [16]. Juvenile idiopathic arthritis, Graves-Basedow disease are observed [17, 18]. Thrombocytopenia and haemolytic anaemia are also observed but the frequency is not known. The cytopenias and other autoimmune diseases are more prone due to altered T regulatory homeostasis [19].

\section{Facial defects and abnormalities}

Dysmorphic facial features are also characteristic of the syndrome. They include an anti-mongoloid position of the eyelids, widely spaced eyes, and the so-called fish mouth caused by an underdeveloped lower jaw and short philtrum, and small low-set ears.

Other abnormalities often relate to the palate and may be the first symptoms of this syndrome. They can be manifested by feeding difficulties - frequent regurgitation of food, swallowing disorders. For this reason, children can inadequately put on weight. These problems may be caused by velopharyngeal insufficiency (the largest number of cases) resulting from muscular hypotonia which can be directly accompanied by the submucosal cleft palate, open cleft palate, cleft lip or tongue, which will greatly enhance the observed abnormalities [20].

\section{Cardiovascular abnormalities}

Defects in the circulatory system are the most important problem of patients with the 22q11.2 microdeletion syndrome. The severity of the defect and the possibility of cardiac surgery directly affect the survival of children with this syndrome [21]. The most common abnormalities include a syndrome of defects known as tetralogy or pentalogy of Fallot, common truncus arteriosus, transposition of the great arteries. Other less common defects include narrowing of the aortic orifice, pulmonary valve stenosis, right aortic arch and syndromes which combine the specific defects. A heart defect may not occur in about $26 \%$ of cases, and these are the most common cases of unrecognized 22q11.2 microdeletion syndrome. As a result of an increased availability of cardiac surgery centres and improved surgical techniques, children with the most severe cardiovascular defects survive and require further multidisciplinary care.

\section{Metabolic and endocrine disorders}

Metabolic and endocrine disorders occur especially in the form of hypocalcemia due to underdevelopment of the parathyroid glands, which results in low levels of PTH (parathyroid hormone). In extreme cases, these disorders can cause tetany [22], or errors - diagnosis of epileptic seizures. They are treated with calcium and vitamin $D$. The symptoms are most common in the neonatal period, with a tendency to disappear around 12-14 months of age. Symptoms of tetany, as a sign of increased demand for calcium, may also occur in older children, especially in adolescence, or in situations of stress, surgery, or in pregnant adults.

\section{Urological and renal abnormalities}

Abnormalities of the urinary tract may also occur in the course of the syndrome [23]. Devriend et al. [24] report on 4 renal and urological malformations among 37 cases of DiGeorge syndrome confirmed by genetic testing. Palacios et al. [25] report on pathology within the kidneys and ureters in as many as 7 of 11 patients with this syndrome.

Anomalies in the construction of kidneys and the urogenital tract (hypospadias) may cause nocturnal enuresis, abnormal urination, or recurrent urinary tract infections, which requires constant care or urological and renal correction [26].

\section{Neurological and psychiatric disorders}

Epilepsy or vertigo sometimes occurs in the syndrome. At a later age concentration, learning, and abstract thinking difficulties may take place [27]. There may also be adap- 
tive disorders in the peer group due to pronunciation difficulties resulting from impaired speech organs. Serious mental disorders such as schizophrenia, depression or bipolar disorder are more often found in the population than in healthy people [28]. The reasons are seen not only in the chromosomal abnormalities, but also in chronic stress and anxiety as a result of childhood experiences (surgery, exposure to pain) [29].

\section{Therapy in DiGeorge syndrome}

Treatment of patients with DiGeorge syndrome has to be comprehensive and multidisciplinary. There is a need for life-saving cardiac surgery (heart defect), and surgery (cleft palate, cleft lip), genetic counselling and genetic testing. In some patients with the deep T lymphocyte deficit with concomitant severe infections and, in some patients with a decrease in the immunoglobulins level, the use of immunoglobulins either as a regular substitution or as an adjuvant therapy in the course of infection, depending on the clinical situation, is recommended. Immunization with live vaccines is contraindicated in patients with a severe immune deficiency (especially in terms of the number and function of lymphocytes). Vaccinations can be implemented in the incomplete 22q11.2 microdeletion syndrome as no increased incidence of adverse vaccine reactions is observed.

Microdeletion syndrome patients after cardiac surgery still require multidisciplinary care. As in other primary immunodeficiencies, there is an increased risk of developing tumours of the immune system cells in this syndrome. These patients require the so-called oncological vigilance and observation in the direction of autoimmune diseases, but these diseases are less common. Children with this syndrome also require care in the field of the so-called early intervention such as occupational therapy, rehabilitation (physical and of speech disorders), educational and psychological support.

The hematopoietic stem cells transplantation was suggested in cases of DiGeorge syndrome but severe symptoms of autoimmunity are the clinical indication. In these cases, the stem cell transplantation is successful, which supports the hypothesis that not the number of $\mathrm{T}$ lymphocytes but the defect of the $\mathrm{T}$ cell function is responsible for clinical symptoms in DiGeorge syndrome [5].

The authors declare no conflict of interest.

\section{References}

1. Buckley RH (2002): Primary cellular immunodeficiencies. J Allergy Clin Immunol 109: 747-757.

2. McLean-Tooke A, Barge D, Spickett GP, et al. (2008): Immunologic defects in 22q11.2 deletion syndrome. J Allergy Clin Immunol 122: 362-367.
3. Paśnik J, Cywińska-Bernas A, Piotrowicz M (2007): The 22q11.2 deletion syndrome: immunological questions. Advances in Hygiene and Experimental Medicine 61: 361-368.

4. Pavlicek A, House R, Gentles AJ, et al. (2005): Traffic of genetic information between segmental duplications flanking the typical 22q11.2 deletion in velo-cardio-facial syndrome/DiGeorge syndrome. Genome Res 15: 1487-1495.

5. Kowalczyk D: DiGeorge Syndrome. Immune disorders in children. K Zeman (ed.). Wyd. Lek. PZWL, Warszawa 2002; 103-107.

6. Bartsch O, Nemeckova M, Kocarek E, et al. (2003): DiGeorge/velocardiofacial syndrome: FISH studies of chromosomes $22 \mathrm{q} 11$ and 10p14, and clinical reports on the proximal 22q11 deletion. Am J Med Genet A 117: 1-5.

7. Ziółkowska L, Kawalec W, Krajewsa-Walasek M (2005): (Diagnostic protocol in children with 22q11.2 microdeletion syndrome). Standard Med 2: 1807-1810.

8. Zeman K, Siwińska-Gołębiowska H. Diagnostic criteria for primary immunodeficiency. Immune disorders in children. K Zeman (ed.). Wyd. Lek. PZWL, Warszawa 2002; 158-167.

9. European Society for Immunodeficiencies. Diagnostic criteria: partial DiGeorge syndrome. November 2008. Available at: http://www.esid.org (last accessed on 31 August 2012).

10. Rodewald HR (2008): Thymus Organogenesis, Annu Rev Immunol 26: 355-388.

11. Gennery AR (2012): Immunological aspects of 22q11.2 deletion syndrome. Cell Mol Life Sci 2012 69: 17-27.

12. Jawad AF, Prak EL, Boyer J, et al. (2011): A prospective study of influenza vaccination and a comparison of immunologic parameters in children and adults with chromosome 22q11.2 deletion syndrome (digeorge syndrome/velocardiofacial syndrome). J Clin Immunol 31: 927-935.

13. Moylett EH, Wasan AN, Noroski LM, et al. (2004): Live Vidal vaccines in patients with partial DiGeorge syndrome: clinical experience and cellular immunity. Clin Immunol 112: 106-112.

14. Kowalczyk D, Zembala M: Other well-defined immunodeficiencies associated with large defects. An outline of clinical immunology. M Zembala M, A Górski A (eds.). Wyd. Lek. PZWL, Warszawa 2001; 30-38.

15. Torfadottir H, Freysdottir J, Skaftadottir I, et al. (2006): Evidence for extrathymic $\mathrm{T}$ cell maturation after thymectomy in infancy. Clin Exp Immunol 145: 407-412.

16. Świerkot J, Lewandowicz-Uszyńska A (2007): Autoimmune disorders in the course of primary immunodeficiency. Centr Eur J Immunol 32: 27-33.

17. Gennery AR, Barge D, O'Sullivan JJ, et al. (2002): Antibody deficiency and autoimmunity in 22q11.2 deletion syndrome. Arch Dis Child 86: 422-425.

18. Davies K, Stiehm ER, Woo P, et al. (2001): Juvenile idiopathic polyarticular arthritis and IgA deficiency in the 22q11 deletion syndrome. J Rheumatol 28: 2326-2334.

19. Halnon NJ, Cooper P, Yu Hui Chen D, et al. (2011): Immune dysregulation after cardiotheracic surgery and incidental thymectomy: maintenance of regulatory $\mathrm{T}$ cells despite impaired thymopoesis. Clin Dev Immunol 2011; 2011: 915864.

20. Leopold C, De Barros A, Cellier C, et al. (2012): Laryngeal abnormalities are frequent in the 22q11 deletion syndrome. Int J Pediatr Otorhinolaryngol 76(1): 36-40.

21. Karolczak MA, Bęc L (2003): Problems in treatment of congenital heart defects associated with defects of other organs: 339-357. Cardiac surgery of children. Selected clinical problems. Skalski JH, Z Religa Z (eds.). Wyd. Naukowe, Katowice; 339-357. 
22. Jakubas-Kwiatkowska W, Błachwicz A, Franek E (2005): Hypocalcaemia in clinical practice - causes, symptoms and treatment. Choroby Serca i Naczyń 2: 232-237.

23. Stewart T L, Irons M B, Cowan JM, et al. (1999). Increased incidence of renal anomalies in patients with chromosome 22q11 microdeletion. Teratology 59: 20-22.

24. Devriendt K, Swillen A, Fryns JP, et al. Renal and urological tract malformations caused by a 22qll deletion. J Med Genet 1996: 33: 349-352.

25. Palacios J, Gamallo C, Garcia M, et al. (1993): Rodriquez JI. Decrease in thyrocalcitonin-containing cells and analysis of other congenital anomalies in 11 patients with DiGeorge anomaly. Am J Med Genet 46: 641-646.

26. Czarnecki PM, Van Dyke DL, Vats S, et al. (1998): A mother with VCFS and unilateral dysplastic kidney and her fetus with multicystic dysplastic kidneys: Additional evidence to support the association of renal malformations and VCFS. J Med Genet 35: 348.

27. Gothelf D, Michaelovsky E, Frish A et al. (2007): Association of the low activity COMT 158 Met allelete with ADHD and OCD in subjects with velocardiofacial syndrome. Int J Neuropsychopharmacol 2007; 10: 301-308.

28. Arnold PD, Siegel-Bartelt J, Cytrynbaum C, et al. (2001): Teshima I, Schachar R. Velo-cardio-facial syndrome: implications of microdeletion 22q11 for schizophrenia and mood disorders. Am J Med Genet 105: 354-362.

29. Gothelf D, Feinstein C, Thompson T, et al. (2007): Risk factors for the emergence of psychotic disorders in adolescents with 22q11.2 deletion syndrome. Am J Psychiatry 164: 663669. 